\title{
Etiology-Specific Mineralization Patterns in Patients with Labyrinthitis Ossificans
}

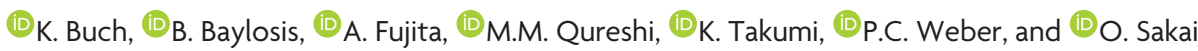

\begin{abstract}
BACKGROUND AND PURPOSE: Our aim was to identify whether specific patterns of ossification in labyrinthitis ossificans are associated with the known risk factors. Labyrinthitis ossificans has been described as sequela of prior temporal bone trauma, prior infection, and other disorders including sickle cell disease. Specific patterns of mineralization in the membranous labyrinth associated with these risk factors has not been previously described.
\end{abstract}

MATERIALS AND METHODS: This was a retrospective study evaluating temporal bone CT scans at our institution from November 2005 to May 2018 in patients with labyrinthitis ossificans. Membranous labyrinthine structures evaluated for ossification included the following: basal, middle, and apical cochlear turns; lateral, posterior, and superior semicircular canals; and the vestibule for both ears in all patients. These structures were assigned a severity score, $0-4$, based on degree of mineralization. Clinical records were reviewed for potential labyrinthitis ossificans risk factors. Basic descriptive statistics and a mixed model were used to correlate the degree and patterns of ossification with clinical history.

RESULTS: Forty-four patients (58 ears) with labyrinthitis ossificans were identified and evaluated. The most common risk factors were chronic otomastoiditis $(n=18)$, temporal bone surgery $(n=9)$, temporal bone trauma $(n=6)$, sickle cell disease $(n=5)$, and meningitis $(n=$ 4). For all etiologies, the semicircular canals were most severely affected, and the vestibule was the least. In patients with prior temporal bone surgery, significantly greater mineralization was seen in the basal turn of the cochlea $(P=.027)$, the vestibule $(P=.001)$, and semicircular canals $(P<.001-.008)$. No significant pattern was identified in patients with meningitis, sickle cell disease, or trauma.

CONCLUSIONS: Significant patterns of mineralization in labyrinthitis ossificans were observed in patients with prior temporal bone surgery. For all etiologies, the semicircular canals were most severely affected. No significant mineralization pattern was observed in patients with chronic otomastoiditis, meningitis, sickle cell disease, or prior temporal bone trauma.

ABBREVIATIONS: AAO-HNS = American Academy of Otolaryngology-Head and Neck Surgery; LO = labyrinthitis ossificans

$\mathbf{L}^{3}$ abyrinthitis ossificans (LO) is a pathologic process involving the ossification of structures within the membranous labyrinth of the inner ear, leading to sensorineural hearing loss. ${ }^{1-8}$ There are typically 3 described phases of LO, including an acute, fibrotic, and ossifying phase. ${ }^{9}$ Ossification has been described on histopathology as starting in the perilymph of the basal turn of the cochlea and then spreading to involve the entire inner ear. ${ }^{9} \mathrm{LO}$ is

Received August 13, 2018; accepted after revision January 5, 2019.

From the Departments of Radiology (K.B., B.B., A.F., M.M.Q., K.T., O.S.), Radiation Oncology (M.M.Q., P.C.W., O.S.), and Otolaryngology-Head and Neck Surgery (O.S.), Boston Medical Center, Boston University School of Medicine, Boston, Mas sachusetts; and Department of Radiology (A.F.), Jichi Medical University, Shimotsuke, Tochigi, Japan.

Please address correspondence to Osamu Sakai, MD, PhD, Department of Radiology, Boston Medical Center, Boston University School of Medicine, FGH Building, 3rd Floor, 820 Harrison Ave, Boston, Massachusetts 02118; e-mail:

osamu.sakai@bmc.org

http://dx.doi.org/10.3174/ajnr.A5985 an uncommon entity with a reported incidence of approximately $2 \%{ }^{10}$; however, it is one of the more common etiologies in patients presenting for cochlear implantation, involving $13 \%$ of these patients. ${ }^{11}$

A multitude of etiologies have been described as potential causes of LO, including otologic infection, infectious meningitis, inflammatory/autoimmune diseases, traumatic injury, iatrogenic injury related to a prior operation, and hematologic causes such as sickle cell disease. ${ }^{1-6,11-14}$ Prior publications on LO comprise mostly case reports, with few studies reporting findings of observational/cross-sectional studies.

High-resolution CT and MR imaging are common modalities for the evaluation of the temporal bone, particularly as a preoperative assessment for cochlear implant placement. ${ }^{15}$ While MR imaging evaluation affords some advantage over high-resolution CT in that it may better assess the intracochlear compartments for obstruction and may better identify the fibrous stages of LO, high- 
resolution CT remains commonly used for the detection of LO. ${ }^{15.16}$ The early identification of LO is important for hearing preservation, early intervention with possible cochlear implant placement, and alerting surgical colleagues to carefully evaluate obstruction during cochlear implant placement. ${ }^{17}$ Significant challenges related to the ability to place the cochlear implant arise with progression of LO and the extent of ossification throughout the membranous labyrinth, which may ultimately lead to alternative cochlear implant insertion techniques. ${ }^{18-20}$ Furthermore, early identification is important because a prior study has suggested a role for treatment with steroids to prevent the progression of LO, particularly for patients with a history of meningitis. ${ }^{21}$

The purpose of this study was to identify potential etiologyspecific ossification patterns in patients with LO using CT.

\section{METHODS AND MATERIALS \\ Patients}

This was a retrospective, institutional review board-approved study performed at Boston Medical Center. Inclusion criteria were patients with hearing loss referred from the otolaryngology clinic who underwent temporal bone CT between November 2005 and May 2018. Patients with LO were identified retrospectively through the radiologic information system using keywords "labyrinthitis ossificans," and CT examinations were retrospectively reviewed. Exclusion criteria were patients with motion-limited CT examinations, which precluded a diagnostic assessment of the temporal bones, and patients with incomplete medical records.

Electronic medical records were reviewed by first-year and fourth-year radiology residents for each of the patients who met the inclusion criteria. Medical record information collected included patient age at the time of the CT scan, sex, and suspected cause of hearing loss, including a history of meningitis, chronic otomastoiditis, sickle cell disease, temporal bone trauma, and prior resection of a temporal bone mass lesion, including vestibular schwannomas or temporal bone cholesteatomas.

A total of 45 patients met the inclusion criteria for this study. One patient was excluded secondary to severe motion artifacts that precluded a diagnostic assessment of the temporal bones, leading to a cohort of 44 patients.

\section{CT Imaging Techniques}

CT studies were performed by 64-detector row multidetector CT (LightSpeed VCT; GE Healthcare, Milwaukee, Wisconsin) $(n=$ 42), 16-detector row multidetector row CT (BrightSpeed VCT; GE Healthcare) $(n=1)$, or an Mx8000 CT scanner (Philips Healthcare, Best, the Netherlands) $(n=1)$. All CT images were helically acquired through the temporal bones; 0.625 -mm-thick images with a $0.3-\mathrm{mm}(n=33)$ or $0.625-\mathrm{mm}(n=10)$ interval reconstruction, or $0.6-\mathrm{mm}$-thick images with a 0.3 -mm-interval reconstruction $(n=1)$, using both bone and soft-tissue reconstruction algorithms.

\section{Image Evaluation}

All images are viewed at an independent workstation (Advantage Windows Workstation; GE Healthcare) with multiplanar reconstructions.

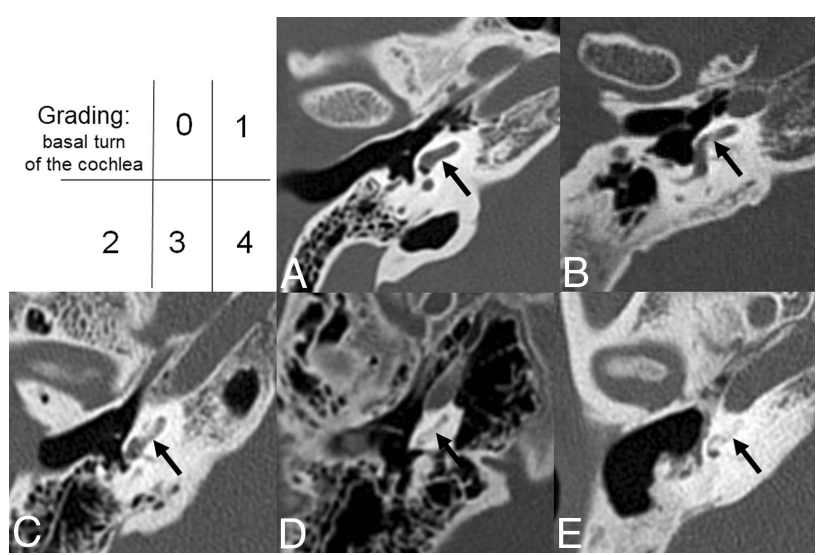

FIG 1. Example of LO mineralization grades $(0-4)$ within the basal turn of the cochlea. Axial, noncontrast temporal bone images through the basal turn of the cochlea demonstrate various grades of mineralization/ossification. $A$, Grade 0 , no evidence of mineralization/ossification. B, Grade 1, mineralization/ossification between $0 \%$ and $25 \%$. C, Grade 2, mineralization/ossification between $25 \%$ and $50 \%$. D, Grade 3, mineralization/ossification between $50 \%$ and $75 \%$. E, Grade 4, Mineralization/ossification of $>75 \%$.

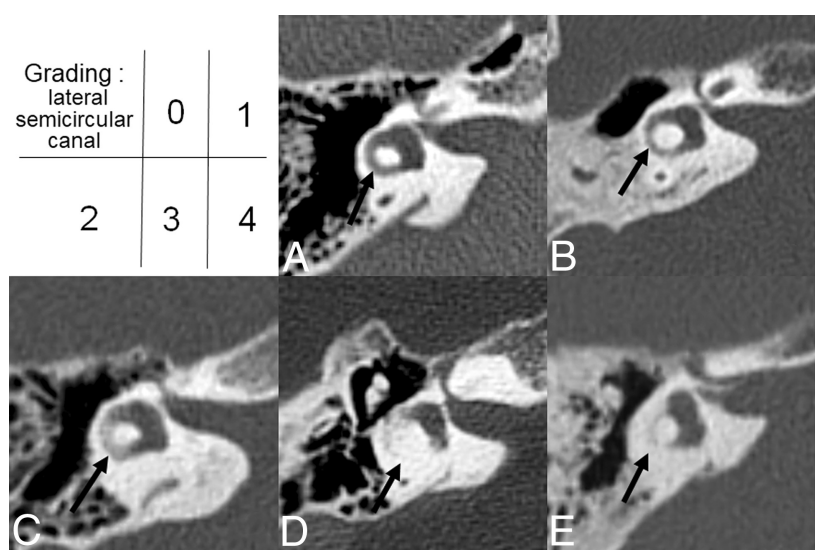

FIG 2. Example of LO mineralization grades $(0-4)$ within the lateral semicircular canal. Axial, noncontrast temporal bone images through the lateral semicircular canals demonstrate various grades of mineralization/ossification. A, Grade 0, no evidence of mineralization/ossification. $B$, Grade 1, mineralization/ossification between $0 \%$ and $25 \%$. C, Grade 2, mineralization/ossification between $25 \%$ and $50 \%$. D, Grade 3, mineralization/ossification between $50 \%$ and $75 \%$. E, Grade 4 , mineralization/ossification of $>75 \%$.

Image evaluation was performed independently by 2 neuroradiologists with $>10$ and 15 years of head and neck imaging experience, blinded to the clinical data, to evaluate the degree of mineralization/ossification. Any discrepancies were resolved by consensus.

Structures of both the right and left membranous labyrinth in all patients were evaluated for the degree of mineralization/ossification. A severity score was assigned to the degree of mineralization/ossification, ranging from 0 to $4(0=$ no mineralization/ ossification, $1=$ up to $25 \%$ mineralization/ossification, $2=25 \%$ $50 \%$ mineralization/ossification, $3=50 \%-75 \%$ mineralization/ ossification, $4=>75 \%$ mineralization/ossification), as illustrated in Figs 1 and 2. Each structure of the membranous labyrinth was assigned its own mineralization/ossification score. Structures per ear evaluated included the following: the basal turn of the cochlea, middle turn of the cochlea, apical turn of the cochlea, vestibule, lateral 
semicircular canal, posterior semicircular canal, and superior semicircular canal.

\section{Audiology Evaluation}

Clinical records were reviewed for audiogram results on all patients included in our cohort. Hearing was stratified by the American Academy of Otolaryngology-Head and Neck Surgery (AAO-HNS) classification. ${ }^{22}$ Correlations between the degree of mineralization within the labyrinth and audiogram results were performed.

\section{Statistical Analysis}

Basic descriptive statistics, including mean and median ossificans grades, were calculated for the patient cohort. For comparison of the mean LO grade by anatomic location, we used paired $t$ tests. A mixed linear regression model was used to correlate the severity of mineralization within the membranous labyrinth and specific clinical risk factors to potentially identify locationspecific patterns of mineralization/ossification. Because each patient could contribute $>1$ ear to the analysis, this approach allows modeling of the variance-covariance matrix among multiple values recorded for each patient. Compound symmetry was specified for the covariance structure. A $P$ value $<.05$ was considered statistically significant. No adjustments for multiple comparisons in determining significance were made. Statistical computations were performed using SAS 9.1.3 software (SAS Institute, Cary, North Carolina).

\section{RESULTS}

\section{Study Population}

The patient cohort comprised 28 women and 16 men, ranging from 3 to 75 years of age (mean age, $39.5 \pm 17.6$ years). Distribution of LO involvement included 18 patients with LO affecting only the right ear, 12 patients with LO affecting only the left ear, and 14 patients with bilateral LO.

\section{Distribution of LO Risk Factors}

Etiologies predisposing patients to LO based on a search of the clinical medical records led to 35 patients with at least 1 risk factor for LO, including the following: 18 patients (23 ears) with chronic otomastoiditis, 4 patients ( 6 ears) with meningitis, 5 patients ( 7 ears) with sickle cell anemia, and 6 patients ( 8 ears) with temporal bone trauma ( 5 patients had no violation of the otic capsule; 1 patient had violation of the otic capsule). There were 9 patients (11 ears) with prior temporal bone surgery, including surgery related to resection of a cholesterol cyst $(n=1$ ear, canal wall down mastoidectomy), cholesteatoma ( $n=5$ ears, 4 ears with canal wall down mastoidectomy, and 1 ear with a canal wall up mastoidectomy and a history of autoatticotomy), and vestibular schwannoma, ( $n=3$ ears, 2 retrosigmoid approaches and 1 translabyrinthine approach). The remaining 2 ears had temporal bone surgery related to tympanoplasty.

Seven of these 35 patients had $>1$ risk factor for LO, including 4 patients with chronic otomastoiditis and a prior operation for treatment of a cholesteatoma, 2 additional patients with a history of sickle cell anemia and prior otomastoiditis, and 1 patient with chronic otomastoiditis and meningitis. Nine patients had no
Table 1: Distribution of labyrinthitis ossificans grade by membranous labyrinthine structures ${ }^{\mathrm{a}}$

\begin{tabular}{llll}
\hline & No. & Mean & SD \\
\hline Overall & & & \\
Apical turn of cochlea & 57 & 0.81 & 1.51 \\
Middle turn of cochlea & 57 & 0.86 & 1.46 \\
Basal turn of cochlea & 57 & 1.04 & 1.48 \\
Vestibule & 58 & 0.55 & 1.14 \\
Lateral semicircular canal & 58 & 1.81 & 1.37 \\
Posterior semicircular canal & 58 & 1.31 & 1.56 \\
Superior semicircular canal & 58 & 1.02 & 1.54 \\
Right side & & & \\
Apical turn of cochlea & 31 & 0.90 & 1.60 \\
Middle turn of cochlea & 31 & 0.94 & 1.48 \\
Basal turn of cochlea & 31 & 1.26 & 1.57 \\
Vestibule & 32 & 0.66 & 1.18 \\
Lateral semicircular canal & 32 & 2.03 & 1.40 \\
Posterior semicircular canal & 32 & 1.50 & 1.59 \\
Superior semicircular canal & 32 & 1.25 & 1.63 \\
Left side & & & \\
Apical turn of cochlea & 26 & 0.69 & 1.41 \\
Middle turn of cochlea & 26 & 0.77 & 1.45 \\
Basal turn of cochlea & 26 & 0.77 & 1.34 \\
Vestibule & 26 & 0.42 & 1.10 \\
Lateral semicircular canal & 26 & 1.54 & 1.30 \\
Posterior semicircular canal & 26 & 1.08 & 1.52 \\
Superior semicircular canal & 26 & 0.73 & 1.40 \\
\hline No: & & & \\
\hline
\end{tabular}

Note:-No. indicates the total number of patients.

${ }^{a}$ LO grades stratified by each structure in the membranous labyrinth and stratified for the left-versus-right ear.

readily identifiable predisposing risk factors for LO based on a search of the electronic medical records.

\section{Bilateral LO Involvement}

A total of 14 patients had LO involving both ears. Four patients had a history of chronic, bilateral otomastoiditis only; 1 patient had a history of chronic otomastoiditis and sickle cell anemia; 1 patient had sickle cell anemia only; 2 patients had a history of meningitis; 2 patients had a history of bilateral temporal bone trauma; 2 patients had a history of temporal bone surgery ( 1 for a retrosigmoid resection of a right-sided vestibular schwannoma; and 1 patient with a translabyrinthine resection of a cholesterol granuloma); and 2 patients had no identifiable risk factor documented in the electronic medical records.

\section{Distribution of Mineralization in LO}

Overall, the semicircular canals were more severely affected compared with the cochlea and vestibules, irrespective of the side, as shown in Tables 1 and 2.

The lateral semicircular canal was more severely affected than the posterior and superior semicircular canals, as well as the apical, middle, and basal turns of the cochlea and the vestibule (Tables 1 and 2). On both sides, the vestibule was the least severely affected.

\section{Mineralization by Risk Factor}

The 18 patients with chronic otomastoiditis demonstrated the greatest degree of mineralization within the lateral, posterior, and superior semicircular canals; however, these findings were not statistically significant (Table 3).

The 4 patients with a history of meningitis demonstrated no 
Table 2: Comparing mean labyrinthitis ossificans grade by anatomic location

\begin{tabular}{|c|c|c|c|c|c|c|c|}
\hline & $\begin{array}{l}\text { Apical Turn } \\
\text { of Cochlea }\end{array}$ & $\begin{array}{l}\text { Middle Turn } \\
\text { of Cochlea }\end{array}$ & $\begin{array}{l}\text { Basal Turn } \\
\text { of Cochlea }\end{array}$ & Vestibule & $\begin{array}{c}\text { Lateral } \\
\text { Semicircular } \\
\text { Canal }\end{array}$ & $\begin{array}{c}\text { Posterior } \\
\text { Semicircular } \\
\text { Canal }\end{array}$ & $\begin{array}{c}\text { Superior } \\
\text { Semicircular } \\
\text { Canal }\end{array}$ \\
\hline Apical turn of cochlea & - & 0.839 & .377 & .371 & .001 & .071 & .423 \\
\hline Middle turn of cochlea & & - & .490 & .256 & .001 & .109 & .539 \\
\hline Basal turn of cochlea & & & - & .061 & .011 & .342 & .966 \\
\hline Vestibule & & & & - & $<.001$ & .004 & .069 \\
\hline Lateral semicircular canal & & & & & - & .060 & .004 \\
\hline Posterior semicircular canal & & & & & & - & .308 \\
\hline Superior semicircular canal & & & & & & & - \\
\hline
\end{tabular}

Note:-indicates analysis is based on 57 ears; data are $P$ values.

Table 3: Comparing mean labyrinthitis ossificans grade by chronic otomastoiditis $^{\mathbf{a}}$

\begin{tabular}{lccc}
\hline & \multicolumn{2}{c}{ Mean (SE) } & \\
\cline { 2 - 3 } & $\begin{array}{c}\text { No Chronic } \\
\text { Otomastoiditis } \\
(\boldsymbol{n}=35)\end{array}$ & $\begin{array}{c}\text { Chronic } \\
\text { Otomastoiditis } \\
(\boldsymbol{n}=\mathbf{2 3})\end{array}$ & $\begin{array}{c}\boldsymbol{P} \\
\text { Value }\end{array}$ \\
\hline Apical turn of cochlea $^{\mathrm{b}}$ & $0.79(0.29)$ & $0.82(0.35)$ & .947 \\
Middle turn of cochlea $^{\mathrm{b}}$ & $0.80(0.28)$ & $0.96(0.34)$ & .720 \\
Basal turn of cochlea $^{\mathrm{b}}$ & $0.98(0.29)$ & $1.23(0.35)$ & .578 \\
Vestibule & $0.44(0.22)$ & $0.76(0.27)$ & .347 \\
$\begin{array}{l}\text { Lateral semicircular } \\
\quad \text { canal }\end{array}$ & $1.81(0.23)$ & $1.74(0.28)$ & .853 \\
$\begin{array}{l}\text { Posterior semicircular } \\
\quad \text { canal }\end{array}$ & $1.13(0.26)$ & $1.54(0.33)$ & .328 \\
$\quad$ Superior semicircular & $0.75(0.26)$ & $1.39(0.32)$ & .136 \\
$\quad$ canal & & & \\
\hline
\end{tabular}

Note:- $n$ indicates the number of ears; SE, standard error.

a $L O$ grade for each structure within the membranous labyrinth is reported stratified by risk factor. $P$ value is from a mixed-effects model.

${ }^{\mathrm{b}}$ Analysis based on 57 ears (34 with no chronic otomastoiditis and 23 with chronic otomastoiditis).

Table 4: Comparing mean labyrinthitis ossificans grade by meningitis $^{\mathrm{a}}$

\begin{tabular}{lccc}
\hline & \multicolumn{2}{c}{ Mean (SE) } & \\
\cline { 2 - 3 } & $\begin{array}{c}\text { No } \\
\text { Meningitis } \\
(\boldsymbol{n}=\mathbf{5 2})\end{array}$ & $\begin{array}{c}\text { Meningitis } \\
(\boldsymbol{n}=6)\end{array}$ & $\begin{array}{c}\boldsymbol{P} \\
\text { Value }\end{array}$ \\
\hline Apical turn of cochlea $^{\mathrm{b}}$ & $0.84(0.23)$ & $0.50(0.71)$ & .657 \\
Middle turn of cochlea $^{\mathrm{b}}$ & $0.88(0.23)$ & $0.72(0.70)$ & .829 \\
Basal turn of cochlea $^{\mathrm{b}}$ & $1.11(0.24)$ & $0.81(0.73)$ & .697 \\
Vestibule $_{\text {Lateral semicircular canal }}$ & $0.63(0.18)$ & $0.04(0.55)$ & .317 \\
Posterior semicircular canal & $1.77(0.19)$ & $1.91(0.56)$ & .806 \\
Superior semicircular canal & $1.22(0.22)$ & $1.96(0.65)$ & .296 \\
\hline
\end{tabular}

a $\mathrm{LO}$ grade for each structure within the membranous labyrinth is reported stratified by risk factor. $P$ value is from a mixed-effects model.

${ }^{b}$ Analysis is based on 57 ears (51 without meningitis and 6 with meningitis).

statistically significant difference in the degree of mineralization within any structure within the membranous labyrinth compared with the 40 patients without a history of meningitis (Table 4).

In the 5 patients with a history of sickle cell disease, no statistically significant difference was noted in the degree of mineralization within any structure within the membranous labyrinth compared with the 39 patients without a history of sickle cell disease (Table 5).

In the 6 patients with a history of temporal bone trauma, no statistically significant difference was noted in the degree of mineralization within any structure of the membranous labyrinth (Table 6). The basal turn of the cochlea, followed by the lateral semicircular canal, was affected the most. The vestibule had the
Table 5: Comparing mean labyrinthitis ossificans grade by sickle cell disease

\begin{tabular}{lccc}
\hline & \multicolumn{2}{c}{ Mean (SE) } & \\
\cline { 2 - 3 } & $\begin{array}{c}\text { No Sickle } \\
\text { Cell Disease } \\
(\boldsymbol{n}=51)\end{array}$ & $\begin{array}{c}\text { Sickle } \\
\text { Cell Disease } \\
(\boldsymbol{n}=\mathbf{7})\end{array}$ & $\begin{array}{c}\boldsymbol{P} \\
\text { Value }\end{array}$ \\
\hline Apical turn of cochlea $^{\mathrm{b}}$ & $0.79(0.24)$ & $0.91(0.65)$ & .858 \\
Middle turn of cochlea $^{\mathrm{b}}$ & $0.89(0.23)$ & $0.67(0.63)$ & .738 \\
Basal turn of cochlea $^{\mathrm{b}}$ & $1.15(0.24)$ & $0.50(0.65)$ & .349 \\
Vestibule & $0.63(0.18)$ & $0.09(0.50)$ & .316 \\
Lateral semicircular canal & $1.84(0.19)$ & $1.40(0.51)$ & .422 \\
Posterior semicircular canal & $1.32(0.22)$ & $1.11(0.60)$ & .747 \\
Superior semicircular canal & $1.09(0.22)$ & $0.37(0.60)$ & .261 \\
\hline
\end{tabular}

${ }^{a} \mathrm{LO}$ grade for each structure within the membranous labyrinth is reported stratified by risk factor. $P$ value is from a mixed-effects model.

${ }^{\mathrm{b}}$ Analysis is based on 57 ears (50 with no sickle cell disease and 7 with sickle cell disease).

Table 6: Comparing mean labyrinthitis ossificans grade by trauma $^{\mathrm{a}}$

\begin{tabular}{lccc}
\hline & \multicolumn{2}{c}{ Mean (SE) } & \\
\cline { 2 - 3 } & $\begin{array}{c}\text { No Trauma } \\
(\boldsymbol{n}=\mathbf{5 0})\end{array}$ & $\begin{array}{c}\text { Trauma } \\
(\boldsymbol{n}=\mathbf{8})\end{array}$ & $\begin{array}{c}\boldsymbol{P} \\
\text { Value }\end{array}$ \\
\hline Apical turn of cochlea $^{\mathrm{b}}$ & $0.75(0.24)$ & $1.15(0.60)$ & .535 \\
Middle turn of cochlea $^{\mathrm{b}}$ & $0.80(0.23)$ & $1.25(0.58)$ & .477 \\
Basal turn of cochlea $^{\mathrm{b}}$ & $1.0(0.24)$ & $1.58(0.60)$ & .372 \\
Vestibule & $0.59(0.18)$ & $0.44(0.46)$ & .763 \\
Lateral semicircular canal & $1.82(0.19)$ & $1.55(0.48)$ & .605 \\
Posterior semicircular canal & $1.36(0.21)$ & $0.50(0.52)$ & .130 \\
Superior semicircular canal & $1.03(0.22)$ & $0.66(0.54)$ & .528 \\
\hline
\end{tabular}

${ }^{a} \mathrm{LO}$ grade for each structure within the membranous labyrinth is reported stratified by risk factor. $P$ value is from a mixed-effects model.

${ }^{\mathrm{b}}$ Analysis is based on 57 ears (49 with no trauma and 8 with trauma).

lowest grade of mineralization. These findings were not statistically significant compared with the 38 patients without a documented history of trauma.

In the 9 patients ( 11 ears) with a history of prior temporal bone surgery for resection of a mass lesion, a significantly higher degree of mineralization was seen in the basal turn of the cochlea, the vestibule, and the semicircular canals compared with the remaining patients with LO who had not had prior temporal bone surgery (Table 7).

\section{Mineralization by Any Etiology}

For the patients with an identifiable risk factor (35 patients), compared with those without an identifiable risk factor ( 9 patients), no statistically significant differences were seen in mineralization grades within the structures of the membranous labyrinth (Table 8). 
Table 7: Comparing mean labyrinthitis ossificans grade by surgery ${ }^{a}$

\begin{tabular}{lccr}
\hline & \multicolumn{2}{c}{ Mean (SE) } & \\
\cline { 2 - 3 } & $\begin{array}{c}\text { No Surgery } \\
(\boldsymbol{n}=\mathbf{4 7})\end{array}$ & $\begin{array}{c}\text { Surgery } \\
(\boldsymbol{n}=11)\end{array}$ & $\begin{array}{c}\boldsymbol{P} \\
\text { Value }\end{array}$ \\
\hline Apical turn of cochlea $^{\mathrm{b}}$ & $0.74(0.24)$ & $1.07(0.51)$ & .553 \\
Middle turn of cochlea $^{\mathrm{b}}$ & $0.74(0.23)$ & $1.41(0.49)$ & .223 \\
Basal turn of cochlea $^{\mathrm{b}}$ & $0.84(0.23)$ & $2.07(0.48)$ & .027 \\
Vestibule & $0.30(0.16)$ & $1.67(0.33)$ & .001 \\
Lateral semicircular canal & $1.49(0.15)$ & $3.04(0.32)$ & $<.001$ \\
Posterior semicircular canal & $0.99(0.20)$ & $2.44(0.43)$ & .004 \\
Superior semicircular canal & $0.75(0.22)$ & $2.13(0.45)$ & .008 \\
\hline
\end{tabular}

${ }^{a}$ LO grade for each structure within the membranous labyrinth is reported stratified by risk factor. $P$ value is from a mixed-effects model.

${ }^{b}$ Analysis is based on 57 ears ( 47 with no prior temporal bone surgery and 10 with prior temporal bone surgery).

Table 8: Comparing mean labyrinthitis ossificans grade by any condition $^{\mathrm{a}}$

\begin{tabular}{lccc}
\hline & \multicolumn{2}{c}{ Mean (SE) } & \\
\cline { 2 - 3 } & $\begin{array}{c}\text { No Risk } \\
\text { Factor } \\
(\boldsymbol{n}=11)\end{array}$ & $\begin{array}{c}\text { Any Risk } \\
\text { Factor } \\
(\boldsymbol{n}=\mathbf{4 7})\end{array}$ & $\begin{array}{c}\boldsymbol{P} \\
\text { Value }\end{array}$ \\
\hline Apical turn of cochlea $^{\mathrm{b}}$ & $0.33(0.49)$ & $0.92(0.24)$ & .280 \\
Middle turn of cochlea $^{\mathrm{b}}$ & $0.22(0.47)$ & $1.03(0.24)$ & .132 \\
Basal turn of cochleab $^{\mathrm{b}}$ & $0.35(0.48)$ & $1.26(0.24)$ & .095 \\
Vestibule $^{\text {Lateral semicircular canal }}$ & $0.01(0.37)$ & $0.71(0.19)$ & .097 \\
Posterior semicircular canal & $1.29(0.40)$ & $1.90(0.19)$ & .181 \\
Superior semicircular canal & $0.65(0.46)$ & $1.44(0.23)$ & .136 \\
\hline
\end{tabular}

${ }^{a} \mathrm{LO}$ grade is reported per membranous labyrinth structure based on patients with an identified LO risk factor compared with those without a risk factor. $P$ value is from a mixed-effects model.

${ }^{\mathrm{b}}$ Analysis is based on 57 ears (11 with no condition and 46 with a condition).

\section{Correlation with Audiogram Results}

Audiogram results were available in 37 of the 44 patients, with 7 ears categorized as AAO-HNS class A, 2 ears categorized as AAOHNS class B, 4 ears categorized as AAO-HNS class C, and 34 ears categorized as AAO-HNS class D. In 6/7 ears categorized as AAOHNS class A, the cochlea had no perceptible mineralization and the semicircular canals were the only structures involved. In the remaining 1/7 AAO-HNS class A ears, both the semicircular canals and all segments of the cochlea were involved. In 1 of the 2 AAO-HNS class B ears, all 3 turns of the cochlea were involved (mineralization score, 2-3). The other AAO-HNS class B ear had mineralization only in the lateral semicircular canal. Three of the 4 AAO-HNS class $\mathrm{C}$ ears had a history of a temporal bone mass lesion. All 4 AAO-HNS class $\mathrm{C}$ ears had mineralization only in the semicircular canals (mineralization score $=1$, in all cases). Marked variation in known LO risk factors, involvement of labyrinthine structures, and mineralization scores was seen in the 34 AAO-HNS class D ears.

\section{DISCUSSION}

A cohort of 44 patients with radiographically proved LO were analyzed. The severity and distribution of mineralization at specific locations within the membranous labyrinth were analyzed and correlated with suspected risk factors for the LO. The results of this study demonstrate a higher grade of mineralization within the labyrinth in patients with a history of temporal bone surgery. For all structures within the membranous labyrinth, the lateral semicircular canal was most severely affected and the vestibule was the least severely affected. In several instances, subtle trends suggestive of etiology-specific patterns of mineralization were observed in this study, including greater mineralization within the lateral semicircular canal in patients with chronic otomastoiditis, a greater degree of mineralization within the basal turn of the cochlea in patients with prior meningitis, a greater degree of mineralization within the cochlea in patients with a history of temporal bone trauma, and significantly greater mineralization within the vestibule in patients with prior temporal bone surgery.

Multiple prior studies have investigated potential etiologies related to LO and the mechanism of cochlear damage. Two studies performed by Kaya et $\mathrm{al}^{23,24}$ evaluating 23 temporal bone specimens with cochlear damage related to serous labyrinthitis, suppurative labyrinthitis, and LO found damage specifically to the spiral ganglion, hair cells, stria vascularis, and spiral ligament with endolymphatic hydrops.

Within the radiology literature, prior publications on LO have focused on case reports and case series describing the occurrence of LO in the setting of infectious etiologies, traumatic etiologies, sickle cell disease, and inflammatory/autoimmune disorders. ${ }^{1-3,8,11,13-14,25}$ This study attempts to fill in gaps in knowledge examining a large cohort of cases of LO related to a variety of underlying suspected etiologies. The patterns of mineralization within the labyrinth based on the suspected underlying etiologies were investigated in an attempt to uncover specific patterns of ossification based on the underlying etiology. One finding noted in this study that has not be previously reported in the literature is a statistically significant increase in mineralization within the vestibule of patients with a history of temporal bone surgery. This finding was unique to patients with prior surgery and was not encountered in patients with other LO risk factors. This may potentially be related to the induction of a local inflammatory process or potentially related to aberrations in fluid dynamics within the labyrinth.

MR imaging may have increased sensitivity for the detection of LO in patients with a fibrous stage of $\mathrm{LO}$ and for the evaluation of subtle and isolated involvement of LO along the scala vestibuli in the proximal basal turn of the cochlea. ${ }^{16,20,26}$ Despite these advantages, high-resolution CT remains a common technique for the evaluation of LO and includes a shorter scan time than MR imaging, which may be easier to tolerate in certain patients.

Recognition and detection of mineralization involving specific components of the membranous labyrinth may have significant impact in the clinical management of these patients, and the use of a mineralization scoring system to grade the severity and location of mineralization within the membranous labyrinth may be important to convey to otologists evaluating patients for cochlear implantation. Specifically, the location of mineralization within the labyrinth and the mineralization score may be helpful for electrode-device selection (based on an inference of the number of viable cells in the spiral ganglion), cochlear electrode implantation technique (apical cochleostomy with retrograde insertion of cochlear implant electrode array), and additional procedural changes, including selection for a circummodiolar drill-out procedure. ${ }^{18,21,27}$ Additionally, the outcome of cochlear implantation may be different depending on the location and degree of ossification/calcification within the labyrinth; for example, elec- 
trical conduction may be different in patients with higher mineralization scores, who may experience more facial nerve stimulation. ${ }^{28}$ These findings may ultimately affect electrode choice and cochlear implant manufacture selection. Therefore, the knowledge of the location and degree of ossification/calcification is important for preoperative patient counseling and postoperative patient training.

There are limitations to this study. First, a small number of patients were included in this analysis. LO is a relatively uncommon entity, and the cohort described reflects the total population of patients with LO who underwent diagnostic CT imaging at our institution. Patients were identified for inclusion into this study on the basis of a review of their imaging findings. We realize that this may introduce a study-selection bias because only patients with LO detected on CT were included in this study. This study describes imaging findings related to LO assessed only by CT. CT remains one of the most common imaging modalities of LO; however, some institutions may also use MR imaging for preoperative evaluation of hearing loss before cochlear implant placement. ${ }^{26}$ CT may be less sensitive for the detection of isolated LO involvement within certain structures, including the scala tympani of the proximal basal turn. ${ }^{20}$ Therefore, patients with involvement of such structures and a fibrous stage of LO may not have been identified.

We had relatively few patients with a history of meningitis compared with a history of chronic otomastoiditis. The distribution of reported LO risk factors in our patient population may not be reflective of a more generalized population, and specific patterns of mineralization should not necessarily be assigned to a specific contributing LO risk factor. The inclusion criteria for this study were based on CT imaging findings of LO; therefore, there is potential bias in this patient cohort and patients with a fibrous stage of LO and very subtle mineralization might not have been included. We are unable to correlate the imaging findings with surgical outcomes because most patients in this cohort did not end up undergoing cochlear implantation, at least not at our institution. Last, this study was performed as an exploratory evaluation; thus, we did not make any adjustment for multiple comparisons in our statistical analysis, and our results should be interpreted with caution.

\section{CONCLUSIONS}

Trends in mineralization patterns within the membranous labyrinth are suggested in this large cohort of patients with LO, with the most severe mineralization observed in the lateral semicircular canals and the least severe mineralization within the vestibule. Overall, the most severe patterns of mineralization were seen in patients with prior temporal bone surgery, with subtle trends in mineralization noted in patients with history of meningitis, chronic otomastoiditis, and temporal bone trauma. Knowledge of these patterns of mineralization may be helpful for practicing neuroradiologists. Additionally, these findings may be helpful for the preoperative assessment before cochlear implantation as discussed; however, additional investigations in this area and on a larger patient cohort are needed.

Disclosures: Osamu Sakai-UNRELATED: Consultancy: Boston Imaging Core Lab.

\section{REFERENCES}

1. Hoffman RA, Brookler KH, Bergeron RT. Radiologic diagnosis of labyrinthitis ossificans. Ann Otol Rhinol Laryngol 1979;88:253-57 CrossRef Medline

2. Swartz JD, Mandell DM, Faerber EN, et al. Labyrinthine ossification: etiologies and CT findings. Radiology 1985;157:395-98 CrossRef Medline

3. Liu BP, Saito N, Wang JJ, et al. Labyrinthitis ossificans in a child with sickle cell disease: CT and MRI findings. Pediatr Radiol 2009;39: 999-1001 CrossRef Medline

4. Saito N, Nadgir RN, Flower EN, et al. Clinical and radiologic manifestations of sickle cell disease in the head and neck. Radiographics 2010;30:1021-34 CrossRef Medline

5. Xu HX, Joglekar SS, Paparella MM. Labyrinthitis ossificans. Otol Neurotol 2009;30:579-80 CrossRef Medline

6. deSouza C, Paparella MM, Schachern P, et al. Pathology of labyrinthine ossification. J Laryngol Otol 1991;105:621-24 CrossRef Medline

7. Saito $\mathrm{N}, \mathrm{W}$ atanabe $\mathrm{M}$, Liao J, et al. Clinical and radiologic findings of inner ear involvement in sickle cell disease. AJNR Am J Neuroradiol 2011;32:2160-64 CrossRef Medline

8. Paparella MM, Sugiura S. The pathology of suppurative labyrinthitis. Ann Otol Rhinol Laryngol 1967;76:554-86 CrossRef Medline

9. Lin HY, Fan YK, Wu KC, et al. The incidence of tympanogenic labyrinthitis ossificans. J Laryngol Otol 2014;128:618-20 CrossRef Medline

10. Nair SB, Abou-Elhamd KA, Hawthorne M. A retrospective analysis of high resolution computed tomography in the assessment of cochlear implant patients. Clin Otolaryngol Allied Sci 2000;25:55-61 CrossRef Medline

11. Khoo JN, Tan TY. Progression of autoimmune inner ear disease to labyrinthitis ossificans: clinical and radiologic correlation. Ear Nose Throat J 2015;94:108-10 Medline Medline

12. Ashfield T, Pai I, Wilson K, et al. Cochlear implantation in children with sickle cell disease. Pediatr Int 2015;57:174-76 CrossRef Medline

13. Dhanjal H, Rainsbury J, Irving RM. Bilateral sensorineural hearing loss and labyrinthitis ossificans secondary to neurosarcoidosis. Cochlear Implants Int 2014;15:337-40 CrossRef Medline

14. Aralaşmak A, Dinçer E, Arslan G, et al. Posttraumatic labyrinthitis ossificans with perilymphatic fistulization. Diagn Interv Radiol 2009;15:239-41 CrossRef Medline

15. Lee TC, Aviv RI, Chen JM, et al. CT grading of otosclerosis. AJNR Am J Neuroradiol 2009;30:1435-39 CrossRef Medline

16. Booth TN, Roland P, Kutz JW Jr, et al. High-resolution 3-D T2weighted imaging in the diagnosis of labyrinthitis ossificans: emphasis on subtle cochlear involvement. Pediatr Radiol 2013;43: 1584-90 CrossRef Medline

17. Trimble K, Blaser S, James AL, et al. Computed tomography and/or magnetic resonance imaging before pediatric cochlear implantation? Developing an investigative strategy. Otol Neurotol 2007;28: 317-24 CrossRef Medline

18. El-Kashlan, Ashbaugh C, Zwolan T, et al. Cochlear implantation in prelingually deaf children with ossified cochleae. Otol Neurotol 2003;24:596-600 CrossRef Medline

19. Philippon D, Bergeron F, Ferron P, et al. Cochlear implantation in postmeningitic deafness. Otol Neurotol 2010;31:83-87 CrossRef Medline

20. Isaacson B, Booth T, Kutz JW Jr, et al. Labyrinthitis ossificans: how accurate is MRI in predicting cochlear obstruction? Otolaryngol Head Neck Surg 2009;140:692-96 CrossRef Medline

21. Hartnick CJ, Kim HH, Chute PM, et al. Preventing labyrinthitis ossificans: the role of steroids. Arch Otolaryngol Head Neck Surg 2001;127:180 - 83 CrossRef Medline

22. Committee on Hearing and Equilibrium guidelines for the evaluation of hearing preservation in acoustic neuroma (vestibular schwannoma): American Academy of Otolaryngology-Head and Neck Surgery Foundation INC. Otolaryngol Head Neck Surg 1995; 113:179-80 CrossRef Medline 
23. Kaya S, Paparella MM, Cureoglu S. Pathologic findings of the cochlea in labyrinthitis ossificans associated with the round window membrane. Otolaryngol Head Neck Surg 2016;155:635-40 CrossRef Medline

24. Kaya S, Schachern PA, Tsuprun V, et al. Deterioration of vestibular cells in labyrinthitis. Ann Otol Rhinol Laryngol 2017;126:89-95 CrossRef Medline

25. Chan CC, Saunders DE, Chong WK, et al. Advancement in postmeningitic lateral semicircular canal labyrinthitis ossificans. $J$ Laryngol Otol 2007;121:105-09 Medline
26. Digge P, Solanki RN, Shah DC, et al. Imaging modality of choice for pre-operative cochlear imaging: HRCT vs. MRI temporal bone. J Clin Diagn Res 2016;10:TC01-04 CrossRef Medline

27. Angeli SI, Goncalves S. Predicting depth of electrode insertion by cochlear measurements on computed tomography scans. Laryngoscope 2016;126:1656-61 CrossRef Medline

28. Nassiri AM, Yawn RJ, Dedmon MM, et al. Facial nerve stimulation patterns associated with cochlear implantation in labyrinthitis ossificans. Otol Neurotol 2018;39:e992-95 CrossRef Medline 